\title{
En torno al concepto de "prescindencia": la corriente sindicalista al frente de la CGT (1930-1935).
}

\author{
Leandro García
}

UNLP

leandrogarcia688@hotmail.com

La Confederación General del Trabajo (CGT) fue creada en septiembre de 1930, pocos días después de producido el golpe de Estado que condujo al gobierno al general José Félix Uriburu y que buscó cancelar las diversas instancias de participación política. En su primer lustro de vida, dicha organización estuvo hegemonizada por la corriente sindicalista, aunque contrabalanceada con una importante representación socialista en los principales cargos directivos. Como todo momento fundacional, la importancia por descifrar las consecuencias de ese origen, producido en condiciones reputadas como adversas, no pasó desapercibido para la historiografia. ${ }^{1}$ En ese sentido, las evaluaciones que pueden hallarse en el campo bibliográfico en relación con el desempeño de dicha organización durante su periodo inaugural han presentado rasgos de llamativa continuidad, a pesar de provenir de muy diversas fuentes y tradiciones académicas (García, 2013: 9-23). Casi de forma unánime, las valoraciones que recibió la actuación de la central obrera durante el lapso transcurrido entre 1930 y 1935 han resaltado la falta de combatividad, la burocratización, la actitud defensiva, la vida vegetativa y el pragmatismo. Dichas conductas de la CGT fueron reiteradamente atribuidas a su decisión de sostener el principio histórico de la prescindencia política, que se asociaba de forma directa a las valoraciones mencionadas (Del Campo: 2005; Matsushita: 1983).

En dicho contexto, se privilegió, además, la búsqueda de conductas y prácticas que permitieran comprender la posterior adhesión al peronismo por parte de importantes sectores sindicales, enfatizando el rastreo

1. Con el consiguiente riesgo de explicar el desenvolvimiento de la institución en cuestión, a partir de la clave que daria su momento originario; el riesgo de que "buscar un tal origen es intentar encontrar "lo que ya estaba dado", lo "aquello mismo" de una imagen exactamente adecuada asi”" (Foucault, 1995: 73).

(Archivos, año V, $\mathrm{n}^{\circ}$ 10, marzo de 2017, pp. 95-115) 
de comportamientos que, de manera más o menos explícita, posibilitaran hacer inteligible dicha relación (Del Campo, 2005; Matsushita, 1983; Falcoff y Dolkart, 1975), con los riesgos analíticos que dicha estrategia suponía (Tortti, 1989: 5-7). Aunque utilitaria para explicar la pérdida de combatividad clasista del proletariado y su acercamiento a la práctica de negociación estatal, cierta interpretación literal y escasamente problematizada de la prescindencia en la que abrevaban estos textos llevó a ignorar aspectos significativos de las concepciones, imágenes, tradiciones y referencias históricas que la dirigencia cegetista transmitió desde sus órganos de prensa oficiales (Boletín de la CGT y CGT) y que contenían -mucho más a menudo de lo que se ha señalado- diversas apelaciones cuyos sesgos combativos, ideológicos y anclados en clivajes de clase resultan visiblemente detectables.

Es así que sostenemos que, al analizar la producción discursiva emanada de la prensa de la CGT referida a las actividades sindicales clásicas como las huelgas y movilizaciones y enfatizando las alusiones a rituales, celebraciones y tradiciones ideológicas se puede lograr una mayor precisión a la hora de interpretar el mensaje que la central dirigió a sus militantes, enmarcándolo en el contexto concreto de las secuelas de la crisis económica que se experimentarian en la primera mitad de la década del 30.

En este mensaje se pueden encontrar innumerables referencias que anclan en una tradición marxista de claro contenido clasista y que desmentirian la endeblez ideológica que se le adjudicó a dicha corriente. Sostenemos que en estos momentos de crisis, la apelación de la dirigencia cegetista refería a un corpus sólidamente establecido en la memoria obrera como estrategia de refuerzo identitario.

\section{La prescindencia y la crisis}

Siendo la corriente sindicalista una de las expresiones más importantes del movimiento obrero, resulta lógico conceptualizar la prescindencia en tanto legado de una tradición insoslayable, que resultó resignificada históricamente ante el contexto de la crisis mundial de $1930 .{ }^{3}$

2. El Boletín de la CGT, de tirada mensual, circuló entre en enero de 1932 y marzo de 1934. A partir del 20 de abril de 1934 comenzó a editarse CGT, de salida semanal; en este trabajo se releva hasta el número 89, publicado el 27 de diciembre de 1935.

3. La CGT surgió de un acuerdo entre la COA (socialista) y la USA (sindicalista) y al momento de su fundación en el que se realiza la primera reunión del Comité Nacional Sindical hubo doce representantes de la primera y once de la segunda. Por la COA participaron: José Negri, Luis María Rodríguez, Bernardo Becerra, Antonio Tramonti, Luis González, Ceferino López, Antonio Melani, Esteban Martinena, Marcelino Ganza, Luis Cerutti, José Domenech (todos de la UF) y José Rodríguez (de la FEC); por la USA: 
En ese sentido, los autores que interpretaron la creación de la CGT como una respuesta a la crisis señalaron, llamativamente, la falta de percepción de la misma acerca de los cambios políticos y, especialmente, en la estructura económico-social que se estaban produciendo a escala nacional e internacional (Del Campo, 2005: 53; Godio, 1989: 31). Sin embargo, esta apreciación dada desde dicha literatura no se verifica en el análisis empírico de las fuentes, al examinar detenidamente los temas que prioriza la prensa cegetista para su difusión. En efecto, la primera preocupación proclamada por los redactores sindicalistas sería la de comprender el "fenómeno social" que se estaba produciendo, señalando que al no ser algo transitorio, había que desentrañarlo. Comprender, en fin, que era lo que estaba en crisis. Ante este desafio que se planteaban, responderian que no era la economía, sino el sistema capitalista todo el que había colapsado. A ello agregaban:

El régimen actual es arbitrario, irracional y bárbaro [...] Todos los principios jurídicos en los que se apoya son absurdos, siendo el más monstruoso el que estatuye el derecho a la propiedad privada. Está en crisis, sí, el régimen capitalista; está enfermo y hay que ayudarle a bien morir [...] La presente generación es la que tiene la obligación de dar el golpe de gracia al capitalismo. ${ }^{4}$

A partir de este texto, de cierto tono apocalíptico, motivado por la necesidad de reafirmar la pertenencia de la clase que en su lucha terminaria con el capitalismo, pueden observarse otros registros del discurso atendiendo los argumentos que lo sustentaban. Los mismos se apoyaban en la información provista por la Organización Internacional del Trabajo (OIT) y la Federación Sindical Internacional (FSI), especialmente en estudios que relevaban el notable aumento del paro forzoso. ${ }^{5}$

Frente a esta situación y como primera acción -en el marco de las restricciones impuestas por la dictadura de Uriburu y en vistas de la "apertura" en el gobierno fraudulento de Justo- la CGT lanzó, en febrero

José Ritta Luz (oficial pintor), Alejandro Silvetti (carpintero), José Milani (calzado) José Evar García (herrero en taller municipal), Abraham Resnik (letrista), Andrés Cabona (obrero en mimbre), Segundo García (calzado), Manuel Blanco (ebanista), Amadeo Chiapella (metalúrgico naval), Segundo Ortiz (tapicero) y José García (calzado). En esta reunión se acordó el nombre de la central y los miembros de la Junta Ejecutiva cuya distribución fue la siguiente: por la COA, Cerutti (secretario general), Negri (protesorero), González, López y Melani (vocales); por la USA, Silvetti (prosecretario), Cabona (tesorero), Resnik, Ortiz y Milani (vocales). Ver Matsushita (1983: 67 y 74).

4.Boletín de la CGT (de ahora en más BCGT), $\mathrm{n}^{\circ}$ 2, 15 de febrero de 1932.

5.BCGT, $\mathrm{n}^{\circ} 17,25$ de mayo de 1932. 
de 1932, el Programa Mínimo, ${ }^{6}$ de rasgos comunes con los de la mayor parte de los países afectados por la crisis, ya "que la CGT hace suyo el programa de reivindicaciones que el proletariado mundial tiene elaborado" a partir de considerar que las circunstancias del país son "el espejo de la realidad de mundo". ${ }^{7}$ La indiferencia tanto del poder ejecutivo como del congreso ante los reclamos cegetistas motivó el lanzamiento del Plan de Emergencia en junio de 1934, cuyo énfasis estuvo puesto en el llamado a la clase obrera a salir de la pasividad -generada por la "monumental crisis"- y en reforzar la organización sindical. Esta campaña produjo la intensificación de la actividad de la CGT con la realización de numerosos actos públicos en teatros, como el Verdi o el Mitre, y en locales sindicales de los tranviarios, ferroviarios y estatales (García, 2013: 52) en los que se reclamó a la militancia retomar el pensamiento de Marx, en tanto se afirmaba que la emancipación de la clase obrera "debe ser obra de ella misma" ya que le corresponde al proletariado "bregar por el advenimiento de un mundo nuevo". ${ }^{8}$

\section{La prescindencia y la ideologia}

Otra recurrencia de la historiografia fue vincular la prescindencia política a cierta carencia, despreocupación y hasta desprecio hacia todo lo relacionado con contenidos filosóficos e ideológicos (Matsushita, 1983: 34-36; Del Campo, 2005: 29-30). ${ }^{9}$

Si bien los argumentos que justificaban esta apelación se basaban en proponer una clara estrategia de organización en pos de la unidad del movimiento obrero, los mismos se sustentaban mediante la invocación a pensadores a los que dificilmente se los pueda identificar como carentes de fundamentos teóricos e ideológicos. Para justificar lo mencionado, puede indicarse que a la hora de buscar referencias históricas se revivió, en las páginas de la prensa cegetista, el debate entre Marx y Bakunin en la Primera Internacional de 1864 que culminó sin lograr la unificación de objetivos y estrategias de acción para el movimiento obrero. Desde los editoriales de la CGT, apelando a una reinterpretación a más de medio siglo de distancia, se resaltó la afirmación de Marx en torno a preservar la independencia de los sindicatos. ${ }^{10}$

En un marco más amplio, la CGT estuvo dentro de la disputa por la

6.BCGT, $\mathrm{n}^{\circ} 2,15$ de febrero de 1932 .

7.BCGT, $\mathrm{n}^{\circ} 4,25$ de abril de 1932.

8.CGT, $\mathrm{n}^{\circ} 10,22$ de junio de 1934.

9.Trabajos recientes, sin embargo, han contrastado esta visión, desde la referencia empírica concreta de algunos de sus dirigentes, como Julio Arraga (Caruso, 2016: 3).

10.CGT, $\mathrm{n}^{\circ} 21,7$ de septiembre de 1934 . 
apropiación del "verdadero legado" del marxismo en la que también participaron partidos políticos, organizaciones obreras y espacios culturales y académicos que se incluyeron en la tradición de dicho pensamiento. Queda claro cuál es la imagen que rescata la CGT para construir su propio Marx cuando se observa el editorial de la página principal del mensuario para conmemorar el cincuentenario de su muerte:

No es posible en una nota de circunstancia como esta evocar la multiforme personalidad de Marx, economista profundo y original, filósofo de la historia, sociólogo insigne y polemista sin igual. Por otra parte, dado el carácter especial de nuestro Boletín, como órgano oficial de una central obrera, nos ha parecido que antes que el Marx economista, el Marx filósofo y el Marx historiador (ya que todo eso y mucho más fue), correspondia recordar al Marx consagrado a los trabajadores, al animador del movimiento comunista e insurreccional de 1848, al organizador y alma de la gloriosa Internacional y al defensor valiente, magistral y mordaz de los heroicos comuneros de París. Ese es el Marx y el marxismo obrero contra el cual, hoy como ayer, están todos los conservadores y reaccionarios. ${ }^{11}$

Cabe destacar que, aunque se hace alusión a cualidades múltiples e inescindibles, el peso destacado se lo otorga a la figura de Marx, en tanto militante vinculado a los movimientos obreros y las acciones politicas concretas. Frente al riesgo de un pensamiento transformado exclusivamente en un legado intelectual o congelado en un saber científico y académico, la CGT, retoma, desde el plano discursivo, al Marx revolucionario. ${ }^{12}$

La voluntad de mantener las prácticas sindicales al margen de compromisos políticos-partidarios ${ }^{13}$ posibilitó a la CGT continuar negociando con el Estado, como lo habian hecho anteriormente otras constelaciones sindicales (Garguin, 2000: 87-117; Del Campo, 2005: 95-96). Dicha negociación no implicó, sin embargo, necesariamente, y más allá de las negociaciones mantenidas con ellos, reconocimiento alguno a los

11.BCGT, $\mathrm{n}^{\circ}$ 15, 25 de marzo de 1933.

12. Es interesante resaltar que esa misma tradición del Marx combativo revolucionario se reivindicaba desde el ala izquierda del Partido Socialista, que en principio, se podría ubicar en las antípodas de la corriente sindicalista (Martínez, 2012). A pesar de ser absolutamente contrarios a la prescindencia, es notable como la izquierda socialista retoma ciertos argumentos que de ninguna manera serian invalidados por los sindicalistas como la recuperación de Marx o los cuestionamientos al parlamentarismo.

13. Aunque con contadas excepciones, como el caso de Bernardo Becerra, quien fue candidato a diputado por el partido Conservador (Del Campo, 2005: 72). 
gobiernos existentes, a los que se consideraba por igual -tal vez bajo una mirada fuertemente ortodoxa en plano ideológico- como regímenes de dominación burguesa (Torre, 1995: 297). Por eso, bajo la mencionada perspectiva, predominarian los mensajes destinados a reforzar la identificación de clase, como puede verse en la convocatoria al mitin del $1^{\circ}$ de mayo de 1932 que llamaba a la unidad de todos los trabadores, ya que "por encima de las diferencias teóricas nos une la misma condición de productores: por encima de la arbitraria división de fronteras y patrias, nos une la roja bandera de la Internacional". ${ }^{14}$

\section{Lecturas sindicalistas en clave local: la prescindencia y la relación partido-sindicato}

Según lo mencionado, el principio de la prescindencia habría funcionado, efectivamente, como factor de unión en la CGT en el marco de la dictadura uriburista; sin embargo, su sostenimiento también reavivó las desavenencias -existentes desde larga data- entre sindicalistas y socialistas, ${ }^{15}$ las que tomarian nueva forma al interior de la central obrera. En ese sentido, a pesar de la histórica tensión y de la variación de las posturas del PS en cuanto a la articulación entre la esfera política y la gremial (Camarero, 2015), la llegada de Justo al poder posibilitó, con importantes restricciones, cierta reactivación de la actividad sindical y política, generando en los dirigentes gremiales de extracción socialista expectativas favorables para la sanción de leyes en el parlamento. ${ }^{16}$ Esto se explica porque con la abstención del radicalismo, el PS logró una considerable cantidad de bancas generando posibilidades concretas para que se aprobaran leyes favorables al movimiento obrero. ${ }^{17}$ Frente a ello, los sindicalistas persistieron en su actitud de preservar la autonomía de la CGT y sin negar de plano la utilidad coyuntural del parlamento no dejaron de expresar sus reparos. Esta postura resultaba tributaria de una tradición que históricamente cuestionó la eficacia de la aplica-

\section{4. $B C G T, \mathrm{n}^{\circ} 2,15$ de febrero de 1932 .}

15. Para la década del 20, como se ha señalado: " $\mathrm{El}$ conflicto entre socialistas y sindicalistas tuvo su primera escenificación en el $11^{\circ}$ Congreso de la FORA, que tuvo lugar en La Plata en febrero de 1921, cuando al iniciarse las sesiones en la ciudad de La Plata, los sectores sindicalistas impugnaron el diploma del socialista Agustín Muzio, a quien se le cuestionaba ser diputado nacional" (Martínez Mazzola, 2011: 16). 16. En este número se publica, asimismo, un texto de Diego Ceruso que analiza esta cuestión.

17. En su análisis de la coyuntura política el PS intuyó la necesidad del régimen de satisfacer algunas demandas de la oposición para darle un marco de "cierta legalidad" a un gobierno surgido del fraude electoral (Matsushita, 1983: 105). 
ción de leyes provenientes del parlamento (Belkin, 2013: 81-106) o de decretos del poder ejecutivo, al considerarlos productos emanados de instituciones burguesas; en una posición que se enlaza coherentemente con el descrédito del sistema político argentino de la década de 1930.

De allí que la actitud sindicalista, que podría ser leída en función de cierta retórica atemporal, cobró actualidad cuando la prensa cegetista denunció casos concretos de leyes que no se cumplieron (García, 2013: 67-71). Este incumplimiento se atribuía a que dicha legislación afectaba los intereses de la clase capitalista, por lo que la CGT convocó a su militancia a plantear la lucha en el terreno económico sin esperar nada de las leyes que siempre constituyeron un "mito", debiendo ser utilizadas como medio transitorio y "nunca como finalidad". ${ }^{18}$

En el marco de sus divergencias con los socialistas y por constituir un problema que excedía la esfera nacional, los sindicalistas colocaron en el centro de la escena los múltiples debates desarrollados internacionalmente en torno al rol específico que tenían que desempeñar las organizaciones obreras. Resultó notorio el incremento tanto de notas editoriales como de reportajes realizados a dirigentes sindicales europeos de indudable representatividad como Edo Fimmen, Ángel Pestaña o León Jouhaux (García, 2013: 73-90). Si bien se buscó una asimilación un tanto lineal entre las discusiones locales y las internacionales, con la manifiesta intención de polemizar con los socialistas de la CGT, no parece que hubiera un forzamiento en cuanto al eje central del debate: la relación entre la esfera política y la sindical. En la Argentina, y más nítidamente en Europa, los fenómenos políticos producidos en la entreguerras reavivaron la polémica acerca del vínculo del movimiento obrero con otras agrupaciones ajenas al mismo. La corriente sindicalista que conducía la CGT buscó, en el plano internacional, las referencias que reafirmaran el principio de la prescindencia, al que sentian fuertemente cuestionado. En torno a esta estrategia se hace inteligible la difusión de los testimonios de dirigentes como el del holandés Edo Fimmen, secretario general de la Federación Internacional de los Obreros del Transporte (ITF) cuando analizó las circunstancias críticas que atravesaba el proletariado austríaco y alemán frente a las experiencias reaccionarias de sus respectivos países. Ante la escasa expectativa que depositaba en una respuesta política de los propios países europeos frente al avance del fascismo, Fimmen exclamaba:

La mayor parte del movimiento obrero europeo ha estado siempre en relación muy estrecha con los partidos políticos. A

18. "Los sastres y el cumplimiento de las leyes obreras", BCGT, n ${ }^{\circ} 4,25$ de abril de 1932. 
su influencia se debe su espíritu. A mi modo de ver, el verdadero movimiento obrero no es el político, sino el sindical. Es este el último que representa la verdadera fuerza de la clase obrera y no el pensamiento de los doctores y escritores que abatirá el capitalismo. Es por eso que yo soy partidario de las más estrechas e intimas relaciones de las organizaciones europeas con las de América Latina y el Extremo Oriente. El movimiento obrero europeo está viejo y muy ligado al sistema capitalista. Necesita nueva sangre. Son los movimientos obreros de esos países los que pueden darle nuevo impulso y nuevas energías. De esa unidad revolucionaria, de la confluencia de los obreros blancos, negros y amarillos surgirá un nuevo mundo iluminado por el color rojo de la bandera proletaria. ${ }^{19}$

Comentario que los sindicalistas leen sin mayores esfuerzos como la ratificación de los principios fundantes de la corriente sindicalista, aunque tal vez la novedad resida en el dejo de frustración transmitido por Fimmen a partir del camino transitado por el movimiento obrero europeo. A la vez que se manifiesta el anhelo, de neto corte internacionalista, de recuperar la iniciativa de la clase obrera desde América Latina y el Extremo Oriente. Interpretación marxista, aunque resignificada por el clima epocal si se tienen en cuenta los reparos de Marx sobre el potencial revolucionario de los proletariados no europeos.

No solo por adoptar la misma denominación es que la CGT argentina haya tomado como una ineludible referencia a su homónima francesa; sus marcas de nacimiento, trayectoria, formas de acción sindical y la mirada histórica acerca del rol que debe desempeñar el movimiento obrero han constituido para la corriente sindicalista local un lugar permanente de reafirmación identitaria. También la central francesa fue acusada de abandonar el carácter revolucionario de sus orígenes para virar hacia posiciones reformistas (Gambone, 2000; Papayanis, 1985). Viraje que se explicó tanto en las discusiones originadas acerca del tipo de organización gremial que se estaba desarrollando en Francia como de los posicionamientos del movimiento obrero ante la Gran Guerra y la revolución bolchevique. Algunos autores sostienen que la CGT de Francia, a partir de la conducción de León Jouhaux, se burocratizó, se hizo conservadora y funcionó como una Trade Union convencional en la que sólo desde la retórica discursiva se sostuvieron las consignas revolucionarias (Gambone, 2000; Papayanis, 1985). Si el atento seguimiento del debate acerca de la preservación de la autonomía del movimiento obrero en diferentes partes del mundo cobró una notable relevancia en

19. "Conversando con el secretario de la Federación Internacional del Transporte", $C G T, \mathrm{n}^{\circ} 11,29$ de junio de 1934. 
la prensa cegetista en tanto extrapolación -más o menos forzada- que permita una interpretación y discusión de problemas locales, las referencias a la CGT de Francia se situaron en un plano más directo cuyo principal objetivo fue encuadrar, sin medias tintas, la disputa con el socialismo. En esa dirección se recordó al socialismo las palabras de su histórico referente, Juan B. Justo, cuando afirmó que:

Con toda su unilateralidad, el sindicalismo ha sido en Francia una reacción saludable contra la tutela que ejercían las fracciones politicas sobre el movimiento obrero gremial, al cual debilitaban con sus disensiones doctrinarias y personales. A medida que el pueblo completa su método de acción y sistematiza todas sus actividades, no pueden ya los hombres concebir que su vida entera obedezca a los cánones de un partido. ${ }^{20}$

Buscando ciertas analogias de las realidades de ambos países, la CGT intentó mostrar los vínculos de aquellas situaciones que ameritaran semejanzas, reproduciendo a la vez que interpretando en clave local las informaciones que se publicaban en el órgano de prensa de la central francesa, Le Peuple. Si bien la rivalidad de la CGT de Francia estuvo planteada con el comunismo desde el momento en que se produjo la escisión del movimiento obrero que dio como resultado la creación de la CGTU (Confederación General del Trabajo Unificada) en el año 1921, el eje del debate en los años 30 retoma la discusión en torno a la preservación de la autonomía del movimiento obrero. ${ }^{21}$ Circunstancia que permitió a la prensa cegetista apropiarse sin demasiada dificultad de un discurso que trasladó a la escena local en pos de equiparar los procesos de ambos países:

Acabamos de leer en Le Peuple, cotidiano de la Confederación General del Trabajo de Francia, un interesante trabajo de la Unión de los Sindicatos Confederados de la región parisina a este respecto y como de su lectura se desprende que alli el movimiento obrero tiene un problema semejante al nuestro,

20. $C G T, \mathrm{n}^{\circ} 16,3$ de agosto de 1934 .

21. Es ilustrativa la perspectiva del secretario administrativo de la CGT de Francia, Raoul Lenoir, cuando en un artículo publicado en La Tribune des Cheminots de París del 15 de septiembre de 1934 afirma que los partidos comunista y socialista de su país "consideran a la organización obrera como su complemento, como la agrupación de hombres subordinada a sus directivas y sujeta a las órdenes de mando que emanan de ellos" ("Por qué defendemos la independencia sindical", CGT, $\mathrm{n}^{\circ} 28,26$ de octubre de 1934). Para seguir el debate entre dirigentes de las centrales francesas (CGT y CGTU), véase "Opiniones acerca de la unidad y la independencia del movimiento sindical”, CGT, n ${ }^{\circ} 51,5$ de abril de 1935. 
nos parece de todo punto de vista oportuno glosarlo en estas columnas. A los lectores les bastará sustituir el nombre del partido comunista de Francia por el socialista de la Argentina y el de la comisión sindical de aquél por el de la Comisión Socialista de Información Gremial de éste para establecer esa similitud. $^{22}$

La intencionalidad de trasladar mecánicamente la realidad de un país a otro sin reparar demasiado en los diferentes contextos sociopolíticos y económicos de cada uno de ellos no implica que no puedan identificarse argumentaciones comunes para utilizar en la controversia. Especialmente cuando se observan algunos comunicados que la CGT de Francia emitió en las reuniones del Comité Nacional Confederal realizado en 1934 que bien podrian asimilarse al debate local:

La CGT estimó que si entre partidos políticos era posible, en ciertos momentos, concretar acuerdos, no era aplicable ese procedimiento en los medios sindicales. La condición de existencia de los partidos constitúyela su pluralidad, su diversidad, en tanto que el sindical, en virtud de las causas que lo promueven, debe ser uno e indivisible. ${ }^{23}$

Sostener la postura de la autonomía sindical no implicó desestimar de plano la posibilidad -y posterior concreción- de realizar acciones conjuntas con otro tipo de organizaciones a partir de la lectura que efectuó la CGT en relación a los procesos sociopolíticos que se estaban produciendo a escala local y global.

Por otra parte, fueron recurrentes las imputaciones recibidas acerca de la inflexible postura sindicalista de plantear la acción gremial exclusivamente en la esfera de la economia, ya que se la interpretó literalmente como una estrategia circunscripta a la obtención de demandas inmediatas para la clase obrera. Mirada que soslaya una larga tradición y una interpretación histórica de la corriente sindicalista, como bien lo explicaba el secretario general de la central francesa al señalar:

Siempre lo mismo en todas partes [...] Cuando aspira a la transformación económica, la Confederación General del Trabajo, conforme a su concepción básica, se mantiene siempre en su terreno, al margen de los partidos políticos. Lo que preconizamos [...], es una verdadera revolución económica. El

22. "Motivos de división en el movimiento obrero. En Francia igual que aquí", CGT, $\mathrm{n}^{\circ} 19,24$ de agosto de 1934.

23. CGT, no 49, 22 de marzo de 1935. 
hombre se libera por etapas sucesivas y a medida que las cadenas que pesan sobre él se hacen demasiado pesadas. [...] El siglo XX nos dará la verdadera libertad, la libertad económica, proporcionando a todos la seguridad material que los progresos científicos, técnicos y filosóficos hacen hoy posible. ${ }^{24}$

Al legitimarse con una figura de la talla de Jouhaux, los sindicalistas argentinos delimitaban las esferas de su propia acción y especificaban las estrategias concretas de lucha del movimiento obrero.

\section{La prescindencia frente al fascismo}

Las reiteradas alusiones de la CGT a las distintas situaciones internacionales buscaron encuadrar los reclamos locales -como los realizados con el Programa Mínimo o el Plan de Emergencia- con los de las centrales de otros países. En un contexto global atravesado por la crisis económica, fenómenos como el fascismo italiano y el ascenso de Hitler al poder en Alemania generaron un fuerte impacto en la escena local que definieron, en buena medida, los alineamientos de distintos actores políticos y sociales (Bisso, 2007: 18). La CGT, como expresión mayoritaria del movimiento obrero, participó activamente de las disputas del momento, cobrando mayor relevancia la que se produjo en relación al peligro de la amenaza fascista. Discusión, que en su devenir, ocasionó el punto más álgido del conflicto con los socialistas, tanto de la central como del partido. Las referencias al fascismo en la prensa cegetista se incrementaron ya sea en los editoriales, en las consignas que convocaban movilizaciones y en las menciones en los actos. Se resalta al fascismo en su matriz claramente delincuencial en relación con los crimenes políticos producidos en Italia (Bisso, 2007: 66) aunque se hacen notar los efectos devastadores que este régimen político está provocando al conjunto de la sociedad y especialmente a la clase obrera, ya que "nunca ha sido mayor que hoy la miseria del proletariado italiano". ${ }^{25}$ En los mítines convocados en un principio se precisaban consignas de mayor amplitud que las referidas de manera específica a la lucha contra el fascismo, al que en un primer momento no se lo nombraba ${ }^{26}$ porque se lo encuadraba en la reacción capitalista, aunque su mención en los

24. Reportaje realizado en la ciudad de Ginebra en junio de 1934, "Hacia una democracia económica en Francia", CGT, n 14, 20 de julio de 1934.

25. BCGT, $\mathrm{n}^{\circ} 16,1$ de mayo de 1933.

26. Por ejemplo, cuando se mencionan tres actos realizados en la Capital Federal "Contra la guerra, la desocupación y la reacción capitalista", BCGT, $\mathrm{n}^{\circ}$ 9, 25 de septiembre de 1932. 
discursos resultó más frecuente frente a los riesgos que implicaba la posible sanción de leyes antiobreras. ${ }^{27}$

En todo caso, la continuidad de los actos convocados por la CGT mostró la participación de dirigentes socialistas como la doctora Alicia Moreau de Justo y Ángel Borlenghi, secretario general de la Federación de Empleados de Comercio (FEC), reflejando una coincidencia en los reclamos de la central como también en la mirada sobre el fascismo en sus rasgos generales. Las interpretaciones fueron adquiriendo un mayor grado de complejidad al incorporar otros ingredientes en la comprensión del fenómeno. Para el dirigente sindicalista José Milani, del Sindicato Obrero del Calzado (SOIC), al fascismo y al nazismo habia que comprenderlos en el marco de la crisis de 1930, ya que si bien en un principio se fundamentaban en el cercenamiento de libertades civiles y especialmente las que competen a las actividades sindicales, su principal objetivo era la recuperación de la rentabilidad capitalista. ${ }^{28} \mathrm{El}$ dirigente afirmaba que el nacionalsocialismo era una "perfecta imitación" del fascismo en la medida en que ambos fenómenos no alteraban los términos que rigen la producción ni su destino, lo cual no solamente no modificaba la matriz de distribución capitalista en cuanto a la riqueza producida por el trabajo sino que la profundizaba. Inclusive, el antisemitismo, como rasgo distintivo del nazismo, también resultó encuadrado en una suerte de "cruzada" que define "el carácter profundamente capitalista y reaccionario de este movimiento". Por lo tanto, se interpretó al nazismo como la profundización de la lucha de clases, consecuencia de la inmediata posguerra que generó un retroceso para el proletariado.

Había preocupación en la dirigencia del movimiento obrero, ya que en el país operaban libremente, desde el inicio del gobierno de Uriburu -y con la anuencia de éste-, bandas paramilitares de tinte fascista como la Legión Cívica Argentina, ${ }^{29}$ a las que parecía que Justo no haría

27. Como el de "Asociaciones gremiales y profesionales" presentado por el conservador Matías Sánchez Sorondo, que fue interpretado por la central como contrario al desarrollo de la vida sindical a partir de ciertas similitudes con la Carta del Lavoro, según el análisis de Marotta, BCGT, n 9, 25 de septiembre de 1932.

28. BCGT, $\mathrm{n}^{\circ} 10,25$ de octubre de 1932 .

29. Una muestra de esta preocupación se pudo apreciar en el acto en el que la FOET conmemoró su quinto aniversario donde se exhortó al gobierno a disolver bandas fascistas como la Legión Cívica o similares (BCGT, $\mathrm{n}^{\circ}$ 19, 25 de julio de 1933). Otras organizaciones menores que articularon sus acciones con la Legión Cívica fueron la Acción Nacionalista Argentina, la Comisión Popular Argentina contra el Comunismo, Asociación Nacional contra el Comunismo, Asociación Patriótica Argentina contra el comunismo (Iñigo Carrera, 2001: 51-52). Específicamente sobre la Legión Cívica: Casco, 2010. 
demasiado por desarticular. ${ }^{30}$ Por eso la CGT, instó a los trabajadores argentinos a reforzar los organismos de defensa sindical para prevenir la gestación de una experiencia similar de este "capitalismo disfrazado con la máscara ultranacionalista" ${ }^{31}$ que tiene como su primordial objetivo destruir las conquistas de la clase obrera. Sin embargo, cuando se trataba de mensurar la verdadera dimensión de la amenaza fascista en la Argentina, algunos análisis modificaron sus énfasis. En un discurso público Borlenghi sostuvo que:

nadie desconoce que el proletariado del mundo está atravesando un duro período de reacción que adquiere características inquietantes, porque se produce con el avance fantástico de fuerzas que integran grandes masas de población. ${ }^{32}$

Se continúa una línea de análisis sobre un fenómeno que se está expandiendo más allá del lugar de origen y se le agrega el elemento del apoyo masivo, no tan presente en las reflexiones precedentes. En cuanto al riesgo de reproducción local, Borlenghi reclamó a los trabajadores a no perder de vista la insinuación de ciertas tendencias fascistas agregando las particularidades de una posible inserción del fenómeno en la Argentina:

Claro que surge a primera vista que aquí los jefes fascistas carecen de lo que podriamos llamar "materia prima". Realmente entre nosotros no hubo una guerra que preparara el ambiente que ellos necesitan; no existen fascistas natos, no hay gente predispuesta a seguir sus pasos, los que se exhiben son unos pocos mercenarios que en cualquier parte existen y que lo mismo sirven en una legión que en un klan. ${ }^{33}$

El riesgo percibido por Borlenghi estaba dado por la posibilidad de que el fascismo se manifieste con otros rostros, porque si bien no se

30. Esta apreciación de la CGT también fue coincidente con algunas miradas contemporáneas provenientes de sectores como la Federación Universitaria de Buenos Aires, cuyo dirigente Ernesto Giúdici acusó al gobierno de Justo de dejar accionar con libertad a las bandas de legionarios, asumiendo una actitud que en el mejor de los casos podría ser caracterizada como complaciente, "Los estudiantes contra el fascismo" (Bisso, 2007: 415-416).

31. "Contra los atentados incalificables del fascismo alemán”, BCGT, n 17, 25 de mayo de 1933.

32. BCGT, $\mathrm{n}^{\circ} 17,25$ de mayo de 1933 .

33. Ibídem. 
apreciaba un anclaje en el pueblo podía ser impuesto desde arriba por una burguesía argentina que como

está enamorada del fascismo y desea implantarlo, tiene que crear el ambiente para ello. Por eso iniciaron la campaña nacionalista, que ni siquiera tiene el mérito de la novedad, ya que todos los tiranuelos de América la han esgrimido sin perjuicio de venderse luego al oro extranjero. ${ }^{34}$

Más allá de la enérgica oposición al fascismo, surgirán ciertas discrepancias en torno a cómo enfrentar el problema (Matsushita, 1983: 109). Mientras Marotta sostenía que la disputa debía desarrollarse exclusivamente en el terreno gremial, porque el fascismo representaba la negación explícita de la libertad sindical, y no por constituir una amenaza hacia una democracia a la que se considera ilusoria, para Borlenghi circunscribir la lucha a un solo ámbito representaría, paradójicamente, una acción corporativa, resultado propio de apreciar a este fenómeno político como otra de las tantas formas de gobierno burguesas. ${ }^{35} \mathrm{Al}$ socialista le inquietaba que la clase obrera pudiera considerar una oferta de reivindicación inmediata ofrecida por un gobierno de tinte fascista, alejando al proletariado de su cometido que es "la transformación de una organización social decadente e incapaz, como lo es la capitalista". ${ }^{36}$ Dificultoso habrá resultado para Borlenghi moverse equilibradamente en la Argentina del primer lustro de la década de 1930 cuando el PS participaba con una significativa presencia parlamentaria legitimando un régimen al cual dificilmente se le pueda atribuir algún atisbo de democracia.

Frente a los balanceos de Borlenghi, el apego -bastante lineal- a los principios doctrinarios sindicalistas posibilitó a Marotta analizar el fascismo desde una perspectiva de clase sin que implicara un posicionamiento sectorial que limitase la comprensión del fenómeno. El dirigente sostuvo que la oposición al fascismo de algunos sectores obligaba al movimiento obrero a dejar sentada su posición. Por eso ironizó acerca de lo proclamado por algunos periódicos -que siempre representaron la

34. Ibídem.

35. Ibídem.

36. "La Confederación General del Trabajo efectuó un acto público contra el fascismo", BCGT, $\mathrm{n}^{\circ}$ 19, 25 de julio de 1933. Otro acto que se llevó a cabo bajo similares consignas fue en la Unión Obrera Local de La Plata, "Acto público por la implantación de la jornada de 6 horas y contra la reacción capitalista"; además la Unión Obrera Provincial de Entre Ríos expresó su posición, "Declaración contra el fascismo", y en el mismo sentido se manifestó el Sindicato de Portuarios de Concepción del Uruguay, $B C G T, \mathrm{n}^{\circ} 18,25$ de junio de 1933. 
histórica tendencia liberal- cuando informaron que la CGT convocaba a un acto de reafirmación democrática. Marotta, referenciándose en Marx, "contesta" que, constituyendo la clase obrera la única fuerza revolucionaria en la sociedad capitalista, jamás puede instituirse en la defensora de un régimen político que personifica los intereses económicos de los sectores dominantes. El dirigente, reiterando su apelación a Marx, señaló que:

La democracia, de acuerdo a la premisa sentada por aquél, es el estado presente capitalista, contra el cual viene luchando el proletariado desde su constitución como clase, y no su aspiración revolucionaria. ${ }^{37}$

La intensificación de la disputa con el socialismo llevó a los sindicalistas a continuar sus reflexiones sobre el fascismo concibiéndolo como un sistema que "resulta históricamente explicable" 38 si se tienen presentes las expectativas que tuvo el pueblo italiano por su pertenencia al bando ganador de la Gran Guerra. El desencanto por los resultados de los tratados de paz tuvo como secuela el desprestigio de las tradicionales agrupaciones burguesas. Descrédito que en buena parte explica el triunfo electoral inmediato de los partidos de izquierda pero que "cuando fueron llamados al poder no se pusieron de acuerdo para aceptarlo". ${ }^{39}$ Situación que al generar un vacío de poder posibilitó el ascenso de un líder cuyo discurso combinó la promesa de satisfacciones inmediatas, incitando a la vez un sentimiento nacionalista a un pueblo "traicionado por los aliados".

La polémica entre sindicalistas y socialistas sobre cómo enfrentar la amenaza fascista cobró mayor intensidad alterando los equilibrios internos que sostenian la unidad de la CGT. En la disputa discursiva los sindicalistas utilizaron el recurso de referenciarse en los argumentos que los socialistas esgrimian desde su propia prensa desde la cual se acusó a la central de subestimar la proliferación de bandas armadas cuando afirmó que no representaban un verdadero peligro, entendiendo que enfocarse en ese aspecto era desviar la atención de las causas que generaron el fenómeno fascista. No se privó la prensa cegetista de transcribir algunos párrafos publicados en el periódico socialista a la hora de realizar una crónica sobre un incidente producido en un acto de la militancia fascista:

37. BCGT, n 19,25 de julio de 1933.

38. $B C G T, \mathrm{n}^{\circ} 23,25$ de noviembre de 1933.

39. Ibídem. 
Del escándalo se ha sabido algo definitivo: que no hay ni movimiento fascista, ni ideales fascistas, ni hombria ni dignidad en ninguno de ellos. La reacción es un conglomerado de vivos y tontos animados en común por la misma ansia de figurar y bienquistarse la confianza de la clase social necesitada de un golpe fascista. ${ }^{40}$

Frente a estas contradicciones -que en definitiva confirmaban las apreciaciones de la CGT- la central se preguntaba sobre los medios que disponían las organizaciones politicas para enfrentar un supuesto avance del fascismo en el país. Se contestó que eran escasas las acciones que pudieran hacer los partidos politicos, ya que han devenido en máquinas electorales que inclusive integran en su organización a sectores económicamente heterogéneos y hasta antagónicos. ${ }^{41}$ Por eso solamente la organización sindical podría presentar una verdadera lucha contra el fascismo al ser la única que la desarrolla en la esfera de la producción, atacando las causas económicas que originaron dicho fenómeno. ${ }^{42}$

El recrudecimiento en la disputa dio lugar a la publicación de uno de los editoriales más significados publicados en la prensa cegetista, cuyo título fue "Prescindencia no implica indiferencia". ${ }^{43}$ La profundización de la discusión llevó a delimitar -nuevamente- en la diferencia que los sindicalistas realizaron entre los "partidos" politicos y las "cuestiones" politicas. Sobre las últimas se precisa que la CGT no es ajena, ya que sus resultados pueden favorecer o perjudicar los intereses del proletariado, pero se insiste en considerar que los problemas politicos tienen su raíz en causas económicas. Se enfatiza que no le atañe al movimiento obrero las querellas de carácter político, filosófico o religioso, lo cual supone un irrestricto respecto a la diversidad de origenes que tuvieron los adherentes a la CGT, cuya pertenencia no se produjo por su condición "de ciudadanos, de ateos o de cristianos, sino de asalariados". ${ }^{44}$ Afirmación de profunda coherencia con la tradición sindicalista-situada en la década de 1930- para fijar posición frente a los socialistas de la CGT y del PS. Se alerta que el "ajetreo de la política" -en el que rara vez se juegan intereses de la clase obrera-, hay partidos que aspiran a que los patrones particulares o bien las entidades que los agrupan financien sus campañas. La consecuencia de este comportamiento partidario es

40. “Tenía razón la CGT", CGT, n 21, 7 de septiembre de 1934. Para ver el editorial al que se hace referencia, La Vanguardia, 2 de septiembre de 1934.

41. Ibídem.

42. Ibídem

43. CGT, $\mathrm{n}^{\circ} 17,10$ de agosto de 1934 .

44. Ibídem. 
la existencia de los profesionales liberales, que "actuando como políticos" aspiran a formar parte de los consultorios médicos o jurídicos de los patrones o de sus empresas. ${ }^{45}$ En cambio, resalta el editorial, tales aspiraciones jamás deberían constituir los objetivos de la organización proletaria en función de que su razón de ser es presentar una lucha abierta contra el capitalismo. ${ }^{46}$

Cabría volver a preguntarse las razones por las cuales se produjo, especialmente desde fines del año 1933, un distanciamiento cada vez más pronunciado entre las corrientes sindicalista y la socialista. Si bien la polémica se manifestó en varios aspectos, tuvo en relación con la estrategia frente al fascismo su punto de mayor controversia, provocando el desplazamiento y la separación de la conducción sindicalista de la CGT en diciembre de 1935.

Este viraje que tuvo la apelación antifascista en relación con constituirse en un elemento que adquiere una fortaleza tal como consigna de lucha en la arena política-partidaria profundizó las diferencias entre socialistas y sindicalistas. En este escenario, los socialistas se movieron más cómodamente ya que habían comenzado a pensar en términos no solamente ligados a la representación sindical, sino necesariamente policlasistas, ya que en la lucha contra el fascismo se consideró ineludible una estrategia de mayor amplitud que incluyera otros actores políticos y sociales. Es factible pensar si no habrá pesado en la conducción cegetista la observación que sostenía que, si bien la consigna antifascista resultó convocante para variopintos actores, subyacian en esta las lógicas tensiones que implicaban su propia heterogeneidad. Los sindicalistas, evidentemente, percibieron las dificultades que a esta multiplicidad de grupos y personas les acarreaba presentar una postura unificada, ya que no sólo diferian en significativos aspectos políticos e ideológicos, sino que -y posiblemente como consecuencia de ello- esas diferencias también hicieron visibles discrepancias en torno a precisar e identificar al fascismo (Bisso, 2007: 21). Divergencias que no tuvieron los sindicalistas tanto a la hora de caracterizar al fascismo como para definir el curso de acción con el que la clase obrera debía enfrentarlo. Para los sindicalistas, esta nueva circulación de la apelación antifascista, expresada incluso en términos en los cuales se difuminaba su significación clasista, generó el problema de interrogarse acerca de si la adhesión a dicha consigna como principal lema de movilización no perjudicaba la afirmación de la identidad obrera. La tenaz persistencia del principio de la prescindencia politica fue la respuesta dada por parte de los sindicalistas, decisión que ahondó las diferencias con los

45. Ibídem.

46. Ibídem. 
socialistas (por ejemplo, en relación con la actitud a tomar frente a las huelgas producidas en esos años) y que explica una de las principales causas de la ruptura de la central en diciembre de 1935.

\section{Conclusiones}

En este trabajo se recuperan cuestiones no del todo ponderadas por una historiografia que, en sus aportes a los estudios del movimiento obrero en la década de 1930, pareció privilegiar la búsqueda de antecedentes del fenómeno peronista en lugar de centrar su foco en la dinámica propia del periodo y en la historia transitada por los protagonistas. Ser tributaria de una línea de análisis de ese tipo condujo a disponer que determinados actores sindicales y politicos ocupasen posiciones establecidas en un reparto de roles que asignó -de manera sumaria y polarizada- el lugar de "ideológicos" para algunos y el de "pragmáticos" para otros. Si bien era una lectura por demás atendible, en relación con la preocupación que la animó, la misma pierde su fortaleza cuando se aspira a enfocar el objeto de estudio desde una multiplicidad de variantes que permita asimismo abrir otros espacios de indagación. En tal sentido se observó, por ejemplo, que no había incompatibilidad entre la emisión de un discurso claramente enmarcado en la ortodoxia marxista y un comportamiento político que se suponía pragmático. Más aún, en la dinámica del primer lustro de la década de 1930, lo que a primera vista se presentó en términos de incongruencia, para la corriente sindicalista que condujo la CGT no tuvo tal significación.

Sería una limitación analítica considerar las prácticas gremiales de los sindicalistas en términos de manipulación o doble discurso. Dicho razonamiento sólo conduce a sostener que la estrategia de la conducción cegetista tiene que ser pensada desde una profunda escisión entre las prácticas discursivas y la acción. Si acordamos con Steinberg (1999) que el discurso asume el carácter de mediador entre la conciencia y la acción, analizar su creación y posterior circulación brindó la posibilidad de comprender, como señala Austin (2006), que la gente realiza cosas con palabras cuyas consecuencias pueden ser tan palpables como otras formas de acción.

En la elaboración del mensaje que la dirigencia cegetista emitió desde su órgano de prensa se ha prestado especial atención a cómo se vivenció una época signada, en principio, por el estallido de la crisis económica mundial de magnitudes desconocidas hasta ese momento y por la implantación de una dictadura militar en el plano local.

Este contexto de crisis inédita condicionó todas las actividades militantes habituales, razón por la cual el mensaje que se intentó transmitir remarcó enfáticamente la necesidad de recuperar las tradiciones obreras 
en lo relativo tanto a las prácticas como a las referencias históricas e ideológicas. Tradiciones que, por supuesto, conservando sus aspectos originales adquirieron nuevas significaciones desde el presente posibilitando comprender y dar sentido a un futuro en el marco de una coyuntura histórica que desde los principales títulos editoriales del periódico cegetista fue caracterizada como "el fin de una era".

Al revisar la imagen corriente en la historiografia y en la memoria politica de la Argentina en la que se ponía el acento fundamentalmente en el "pragmatismo" y en el "apoliticismo" de la dirigencia que condujo la CGT entre los años 1930 y 1935, y a pesar de verificar dicha imagen en algunas prácticas y discursos, queda claro que tanto en la justificación de la necesidad imperiosa de lograr la unidad como en la apreciación de los fenómenos locales e internacionales, los sindicalistas consideraron imprescindible su vinculación e identificación con las tradiciones históricas e ideológicas del movimiento obrero como elemento de legitimación al interior de la clase. Referencias históricas en las que el uso de la tradición puede entenderse, por un lado, como conjunto de prácticas fundamentalmente simbólicas y rituales que buscan una continuidad con el pasado a través de reafirmar valores y comportamientos (Hobsbawm y Ranger: 2002). Pero, complementando dicha interpretación, se puede aseverar que las referencias constantes de la dirigencia cegetista a las tradiciones obreras agregaban la necesidad y capacidad de elaborar estrategias de reinvención de las mismas y su recreación creativa a partir de la interacción con las prácticas cotidianas.

En todo caso, la necesidad de profundizar en el estudio de las experiencias politicas y organizacionales puntuales y concretas del sindicalismo argentino durante su historia resulta una tarea fructifera a desarrollar que aportará, sin duda alguna, elementos para constituir nuevas ideas e interpretaciones que superen el sesgo con el que fue visto dicho movimiento.

\section{Bibliografia}

Austin, John (2006), Cómo hacer cosas con palabras: Palabras y acciones, Buenos Aires: Paidós.

Belkin, Alejandro (2013), "La crítica del sindicalismo revolucionario argentino al parlamentarismo (1905-1912)", en Archivos, n 3.

Bisso, Andrés (2007), El antifascismo argentino, Buenos Aires: CedinciBuenos Libros.

Camarero, Hernán (2015), "El Partido Socialista de la Argentina y sus espinosas relaciones con el movimiento obrero: un análisis del surgimiento y disolución del Comité de Propaganda Gremial, 1914-1917”, Izquierdas, Santiago de Chile, $n^{\circ} 22$, pp.158-179. 
Caruso, Laura (2016), "El gran barco: el sindicalismo revolucionario argentino a través de la obra de Julio Arraga", Izquierdas, n 30, pp. 1-25.

Casco, Christian (2010), Salir a asustar te protege más. Análisis de las prácticas politicas y de la recepción de los discursos ideológicos en la Legión Civica Argentina, tesina de licenciatura en Historia, UNLP.

Del Campo, Hugo (2005), Sindicalismo y peronismo. Los comienzos de un vínculo perdurable, Buenos Aires: Siglo XXI.

Falcoff, M. y R.H. Dolkart (1975), Prologue to Perón: Argentine in Depression and War, Berkeley: University of California Press.

Foucault, Michel (1995), "Nietzsche, la genealogia y la historia", en Oscar Terán, Discurso, poder y subjetividad, Buenos Aires: El cielo por asalto, pp. 71-95.

Gambone, Larry (2000), Reforma y revolución: moderados y revolucionarios en la CGT francesa. El anarquismo y el sindicalismo, en http:/ /dwrdmac. ptizrer.edu/Anarchist_Archive/wordwidemovementts/reforma.html.

García, Leandro (2013), "Animarse a la prescindencia. La lógica de la construcción político-ideológica de la corriente sindicalista en la CGT (19301935)", tesis de maestría en Ciencias Sociales, Universidad Nacional de La Plata.

Garguin, Enrique (2000), "Relaciones entre Estado y sindicatos durante los gobiernos radicales, 1916-1930", en José Panettieri (comp.), Argentina: trabajadores entre dos guerras, Buenos Aires: Eudeba, pp. 87-117.

Godio, Julio (1989), El movimiento obrero argentino (1930-1943). Socialismo, comunismo y nacionalismo obrero, Buenos Aires: Legasa.

Hobsbawm, Eric y Terence Ranger (2002), La invención de las tradiciones, Barcelona: Crítica.

Iñigo Carrera, Nicolás (2001), "La huelga general política de 1932: descripción de los inicios de un ciclo en la historia de la clase obrera argentina", en Publicación del Programa de Investigación sobre el Movimiento de la Sociedad Argentina (PIMSA), Documentos y Comunicaciones.

Martínez Mazzola, Ricardo (2011), "La neutralidad como problema y como solución. La política gremial del Partido Socialista después de la ruptura sindicalista", Identidades, Comodoro Rivadavia, pp.1-20.

Martínez, Ilana (2012), Por la vuelta a Marx. El ala izquierda del Partido Socialista Argentino, 1929-1935, tesis de maestría, Universidad Nacional de General San Martín.

Matsushita, Hiroshi (1983), Movimiento obrero argentino, 1930-1945, Buenos Aires: Siglo XX.

Papayanis, Nicholas (1985), "Alphonse Merrheim. The emergence of reformism in revolutionary syndicalism, 1871-1925", en Studies in Social History, vol. 8. (ed. por M. Nijhoff).

Steinberg, Marc W. (1999), "El rugir de la multitud: repertorios discursivos y repertorios de acción colectiva de los hiladores de seda de Spitalfields, en el Londres del siglo XIX", en Javier Auyero (comp.), Caja de herramientas. El lugar de la cultura en la sociologia norteamericana, Bernal: UNQ. 
Torre, Juan Carlos (1995), "La trayectoria de la vieja guardia sindical antes del peronismo", en Waldo Ansaldi, Alfredo Pucciarelli y José Villarroel, Representaciones inconclusas. Las clases, los actores y los discursos de la memoria, 1912-1946, Buenos Aires: Biblos.

Tortti, María Cristina (1989), "Estrategia del partido socialista. Reformismo político y reformismo sindical", en Conflictos y procesos de la historia argentina contemporánea, 34, Buenos Aires: CEAL.

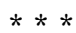

Titulo: Around the concept of "prescindencia": the syndicalist current at the head of the CGT

Resumen: El presente artículo revisa la actuación de la corriente sindicalista al frente de la Confederación General del Trabajo, durante el primer lustro de vida de dicha central obrera (1930-1935). Para ello, se focaliza en la interpretación que los mismos actores sindicales dieron del concepto de "prescindencia", en un enfoque históricamente situado, que remarca la complejidad y flexibilidad de los usos político-ideológicos de esa apelación, y que -según se sostiene aquí- han sido poco atendidos por la historiografia del período, mayormente interesada en explicar dicho fenómeno, no tanto en sus propios términos, como en su condición de antecedente del masivo apoyo otorgado por el movimiento obrero y la dirigencia sindical al peronismo.

Palabras clave: CGT - sindicalismo - prescindencia - crisis de 1930

\begin{abstract}
This article attempts to reexamine the performance of sindicalismo during its leadership of the Confederacion General del Trabajo, on the first years of activity of this organization. The text focuses on "prescindencia" (non-participating policy) as a complex and flexible term and on the uses that sindicalistas gave it on their own signification. This approach -historically situated-discuss with other historiography that privileged the sindicalista phenomenon as merely a background of the relationship between peronismo and working class.
\end{abstract}

Keywords: CGT - non-participating policy - sindicalism - 1930's crisis.

Recepción: 21 de enero de 2017. Aprobación: 4 de marzo de 2017. 